\title{
Awareness and Attitude to the Risk of Cervical Cancer and Screening Method Among Women in the Najran Region of Southern Saudi Arabia
}

Majed Saeed Alshahrani ( $\sim$ alkozeem@hotmail.com )

Najran University College of Medicine https://orcid.org/0000-0001-9718-6371

Salem Ali Alatef Sultan

Najran University College of Medicine

\section{Research Article}

Keywords: awareness, cervical cancer, Pap smear, vaccination

Posted Date: June 26th, 2020

DOI: https://doi.org/10.21203/rs.3.rs-37387/v1

License: (c) (1) This work is licensed under a Creative Commons Attribution 4.0 International License.

Read Full License

Version of Record: A version of this preprint was published at International Journal of Medicine in Developing Countries on January 1st, 2020. See the published version at https://doi.org/10.24911/IJMDC.51-1605075811. 


\section{Abstract}

Introduction:The aim of this study was determined the level of awareness among women regarding risk factors for cervical cancer and screening methods, their sources of information, and general attitudes toward Pap smear screening tests and human papilloma virus vaccination.

Method:A cross-sectional interviewer administered an electronic questionnaire among women in Najran City during the period from March 1, 2019 to June 30, 2019. The data were analyzed using IBM SPSS Statistics for Windows, Version 25.0. Armonk, NY: IBM Corp.

Result: A total of 3,387 women participated in this study and the response rate was $100 \%$. Less than $10 \%$ of the participants had good awareness and $70 \%$ had poor awareness about the risk factors for cervical cancer. In terms of the major barriers to taking the Pap smear test among married women, $968(56.7 \%)$ had no knowledge of the test and 338 (19.85\%) considered it unnecessary. Significant predictors of the level of awareness about cervical cancer and Pap smear testing were identified as the age of women, occupation, family history of cancer, monthly income $(P<0.001)$ and education level $(P=0.003)$.

Conclusion: we detected a lack of awareness about risk factors for cervical cancer and the benefits of early detection among women in this region. Healthcare providers should implement policies or programs for cervical cancer screening and vaccination throughout all primary healthcare centers.

\section{Introduction:}

The cervical cancer is a major health problem in the world. It is the second most common cancer in women living in less developed regions, with an estimated 570,000 new cases reported in 2018 (84\% of all new cases worldwide). In 2018, approximately 311,000 women died from cervical cancer; more than $85 \%$ of these deaths occurring in low- and middle-income countries.[1] Cervical cancer is one of the most preventable and curable forms of cancer, as long as it is detected early and managed effectively.

The reported incidence of cervical carcinoma is low in Saudi women due to the lack of national screening programs. According to the report by the Saudi National Cancer Registry 2015, 1.5\% of women in Saudi Arabia were diagnosed with cervical cancer among women how diagnosed with cancer [2]. The risk of developing cervical cancer is associated with early age of first intercourse, multiple sexual partners, smoking and human papillomavirus (HPV) infection [3].

The incidence of cervical cancer in the United States has decreased by more than $50 \%$ in the past 30 years because of widespread screening [4]. A simple screening test can detect pre-invasive, and invasive disease in the very early stages, when it can be prevented, treated, and cured. The American Cancer Society recommends that all women should begin cervical cancer testing (screening) at age 21. The high mortality rate from cervical cancer globally could be reduced through a comprehensive approach that includes prevention, early diagnosis, effective screening and treatment programs. 
A relatively low prevalence of abnormal smears and cervical cancer has been reported in Muslim countries compared to that in Western populations. Probable explanations for this difference include sexual behavior under Islamic rules [5].

Studies conducted in Saudi Arabia showed that $89 \%$ of cervical cancers were associated with HPV infection, with $78.7 \%$ of HPV-positive tumors infected with HPV-16/18. These strains caused the cancer to appear 5 years earlier than the combined HPV-negative and other HPV genotypes [6]. The Papanicolaou (Pap) smear screening test decreases the incidence mortality of cervical cancer [7]; however, no program of such testing has been implemented in the healthcare sector in Saudi Arabia.

The World Health Organization (WHO) demonstrate that education of the target population combined with the availability of a screening program and treatment in the early stages of invasive cancer of the cervix, has an important effect in reducing the morbidity and mortality from the disease. It is important that the educational programs are designed with consideration for the culture of the country, and that the myths that tend to be prevalent about cancer are addressed.

The aim of this study was to determine the level of awareness regarding risk factors for cervical cancer and screening methods among women in the Najran region of southern Saudi Arabia, their sources of information, and their general attitudes toward Pap smear testing and HPV vaccination.

\section{Methods:}

We conducted a cross-sectional interviewer administered study among women in Najran City Saudi Arabia during the period from March 1, 2019 to June 30, 2019. The study took place in a girls' school, a Maternity and Children's Hospital, King Khalid Hospital and Najran University in Najran City, Saudi Arabia. All females who agreed to participate in the study were included by verbal concent through answerd the questionnior in front of data collectors; no exclusion criteria were applied. The sample size we included all the participant who agreed during this period a total of 3,387 participants. This study received ethics approval from the Research Committee of the College of Medicine, Najran University and the Research Committee of the General Directorate of Health Affairs Najran IRB log Number: 2019-008E. All data were collected through direct interviews using an electronic questionnaire.

The data were analyzed using IBM SPSS Statistics for Windows, Version 25.0. Armonk, NY: IBM Corp. Chi-squared tests/Monte Carlo exact tests and Fisher's exact tests were used to evaluate associations between sample characteristics and knowledge level. Two-tailed tests were used for statistical analyses, with an alpha error of 0.05. $P$-values $>0.05$ were considered to indicate statistical significance. Correct and incorrect answers were assigned scores of one point or zero points, respectively, and the discrete scores for the different knowledge domains were summed. Awareness scores presented as a percentage of the maximum score were categorized as follows: "poor" <50\%, "moderate" 50\%-75\%, and "good" $>75 \%$. 
The researcher used a self-administered questionnaire designed to obtain the following information: 1) sociodemographic data, including age, nationality, educational level, occupation, marital status, medical history and monthly income; 2 ) knowledge of risk factors for cervical cancer and screening methods; and 3 ) attitude and barriers to screening of cervical cancer.

\section{Results:}

The total of 3,387 women and girls participated in this study. The sociodemographic characteristics of the participants are shown in Table 1. Among the participants, 50.5\% were in the 18-29 years age range and $94.8 \%$ were Saudis. In total, $40.9 \%$ of the participants did not work and $20.8 \%$ were school teachers. In addition, $70.4 \%$ of the participants were educated to university level and above. Furthermore, $47.5 \%$ of participants had a monthly income of less than 5,000 Saudi Riyals. Among the participants, $5.6 \%$ and $2.8 \%$ were suffering from diabetes mellitus and hypertension, respectively, and $21.7 \%$ had family history of any type of cancer.

Details of the awareness scores of the participants regarding risk factors for cervical cancer are shown in Figure 1. Less than $10 \%$ of the participants had good awareness about the risk factors for cervical cancer, $20 \%$ had moderate awareness and $70 \%$ had poor awareness.

Details of the awareness and attitude of married women to Pap smear testing are shown in Table 2. Among 1,990 participants who were married, divorced and widowed, 1,024 (51.5\%) were aware of Pap smear testing, but only 282 (14.2) had actually been screened, and of these, 197 (69.9\%) had been advised to do so by doctors. In terms of the major barriers to taking the Pap smear test among married women, $968(56.7 \%)$ had no awareness of the test and 338 (19.85\%) considered it unnecessary.

Details of the awareness and attitude of participants about vaccination against cervical cancer are shown in Table 3. Among the participants, 2,983 (88.1\%) considered that cervical cancer can be prevented by vaccination, but only $530(14.8 \%)$ had been vaccinated and had done so on the advice of a physician, social media or friends and family.

The distribution of predictors of the general awareness scores of cervical cancer is shown in Table 4. Significant predictors of the level of awareness about cervical cancer and Pap smear testing were identified as the age of women, occupation, family history of cancer, monthly income $(P<0.001)$ and education level $(P=0.003)$.

\section{Discussion:}

Cervical cancer is a major public health problem throughout the world. Cervical cancer is the forth most common cancer in women worldwide [8]. The Pap smear it can decrease the incidence of cervical cancer due to early detection. Good awareness about Pap smear screening and the risk factors for cervical cancer decrease the associated mortality and morbidity. In the present study, we show low percentage of the participants were aware to risk factors for cervical cancer and more than half of married women were 
aware of Pap smear testing, although few of them had been screened. In total, a third of participants were aware that HPV is a cause of cervical cancer. A study conducted in Jeddah, Saudi Arabia, showed that low percentage of women were aware of the link between HPV and cervical cancer [9]. A similar study conducted in Riyadh showed that a third of participants were aware of HPV and $27.4 \%$ were aware of its relationship within cervical cancer [10]. Furthermore, in a study conducted in Tanzania, less than half of the nurses who participated had adequate awareness regarding cervical cancer [11]. In comparison, a study conducted in Saudi Arabia showed a good overall knowledge level about cervical cancer (78.6\%), although the knowledge regarding HPV (16.4\%) was low[12]. A similar study conducted in Malaysia (88.8\%) revealed a high level of knowledge about cervical cancer [13].

Among the married participants, approximately half were aware of the Pap smear test, but only $14.2 \%$ had been screened. Of the participants tested, $69.9 \%$ did so on the advice of a physician. In total, $56.7 \%$ of the participants had no awareness of the screening test and $18.9 \%$ considered it unnecessary. In a similar study conducted in Jeddah, $67.6 \%$ of participants were aware of the Pap smear test, but only $16.8 \%$ had been screened, mainly due to lack of awareness [9]. In comparison, a study in Eastern Nigeria revealed that $41.5 \%$ of participants were aware of the Pap smear test but, only $20.5 \%$ had been screened, with most of these participants considering the test to be unnecessary [14]. Also, another study in Al-Ahsa showed that $55.4 \%$ of participants were aware of the Pap smear test, but only $11.2 \%$ had been screened [15]. Participants in this study also reported pain and fear of results as reasons for not being screened. These findings are consistent with another study in which fear was reported as a barrier to screening [16].

Vaccination against HPV decreases the morbidity and mortality of cervical cancer. Therefore, a high level of awareness about cervical cancer may result in increased uptake of screening and the implementation of such preventive strategies. Our study showed that $88.1 \%$ of participants accepted that cervical cancer is preventable, of which $57.2 \%$ were aware of the availability of a vaccine, although only $14.8 \%$ had been vaccinated on the advice of a physician or social media. In comparison with other studies in Saudi Arabia, only $20.8 \%$ of participants in a study conducted in Mecca were aware of the HPV vaccine and only $1.4 \%$ had actually been vaccinated [17]. Moreover, in the study in Al-Ahsa, only $21.1 \%$ of participants were aware of the HPV vaccine, and only $2.1 \%$ had received the vaccine [15].

Multiple logistic regression analyses in our study showed that age, education level, occupation, family history and monthly income had a significant effect on awareness of risk factors for cervical cancer, Pap smear testing and vaccination. The ages of the participants with good awareness of cervical cancer age ranged from 30 to 39 years. Also, in terms of occupation, the participants working in healthcare or in the medical field had good awareness. Furthermore, participants with a family history of cancer and monthly income exceeding 15,000 SR had a good knowledge .

The finding of our study highlight the need to educate women about risk factors for cervical cancer and the benefits of preventive measures such as Pap smear testing and vaccination. Such strategies will be important in increasing the uptake of Pap smear screening and vaccination. Implementation of screening 
and vaccination programs delivered through schools, universities, healthcare providers, social media and home visiting will improve the awareness of cervical cancer.

\section{Conclusion:}

This study demonstrates a lack of awareness about the risk factors for cervical cancer and the benefits of early detection. Healthcare providers should implement policies or programs for cervical cancer screening and vaccination throughout all primary healthcare centers to encourage participation. Such programs require the cooperation of multidisciplinary teams of physician, nurses' educators and psychologists to explain the benefits of screening and early management of cervical cancer.

\section{Declarations}

This study received ethics approval from the Research Committee of the College of Medicine, Najran University and the Research Committee of the General Directorate of Health Affairs Najran IRB log Number: 2019-008E. All participants in this study will remain anonymous.

\section{Availability of data and material:}

Available

\section{Competing interests:}

The authors declares that they have no competing interests.

\section{Funding:}

Self-funding by researchers.

\section{Acknowledgements:}

The author would like to thank Medical Interns for their assistance us in data collections. We would like to thank escienta (www.escienta.com) for English language editing.

\section{Authors' contributions}

All authors contributed the study conception,design. Data alanlysis and interpretation: SS. Drafting the manuscript: MA. All authors discussed the result and contributed to final manuscript.

\section{References}

[1] https://www.who.int/en/news-room/fact-sheets/detail/human-papillomavirus-(hpv)-and-cervicalcancer 
[2] https://nhic.gov.sa/eServices/Documents/E\%20SCR\%20final\%206\%20NOV.pdf

[3] Parkin DM, Bray FI, Devesa SS: Cancer burden in the year 2000: the global picture. Eur J Cancer. 2001; 37(suppl 8):S4-S66.

[4] Practice Bulletin No. 168: Cervical Cancer Screening and Prevention Obstetrics \& Gynecology: October 2016 - Volume 128 - Issue 4 - p e111-e130 doi: 10.1097/AOG.0000000000001708

[5] Jamal AA, Al-Maghrabi JA. Profile of Pap smear cytology in the Western region of Saudi Arabia. Saudi Med J. 2003; 24: 1225-9.

[6] Alsbeih G, Ahmed R, Al-Harbi N, et al. Prevalence and genotypes' distribution of human papillomavirus in invasive cervical cancer in Saudi Arabia. Gynecol Oncol. 2011;121(3): 522-6.

[7] Elovainio L, Nieminen P, Miller AB. Impact of cancer screening on women's health. Int J Gynaecol Obstet. 1997; 58: 137-47.

[8] Bray F, Ferlay J, Soerjomataram I, Siegel RL, Torre LA, Jemal A. Global cancer statistics 2018: GLOBOCAN estimates of incidence and mortality worldwide for 36 cancers in 185 countries. CA Cancer J Clin. 2018;68(6):394-424. doi:10.3322/caac.21492

[9] Sait K. Attitudes, knowledge, and practices in relation to cervical cancer and its screening among women in Saudi Arabia. Saudi Med J. 2009; 30(9): 1208-12.

[10] Hussain AN, Alkhenizan A, McWalter P, et al. Attitudes and perceptions towards HPV vaccination among young women in Saudi Arabia. J Family Community Med. 2016; 23(3): 145-50.

https://doi.org/10.4103/2230-8229.189107

[11] Urasa M, Darj E. Knowledge of cervical cancer and screening practices of nurses at a regional hospital in Tanzania. Afr Health Sci. 2011; 11: 48-57.

[12] Malibari SS. Knowledge about Cervical Cancer among Women in Saudi Arabia. The Egypt J Hosp Med. 2018; 70: 1823-25.

[13] Khoo CL, Teoh S, Rashid AK, et al. Awareness of cervical cancer and HPV vaccination and its affordability among rural folks in Penang Malaysia. Asian Pac J Cancer Prev. 2011; 12:1429-33.

[14] Ubajaka, C., et al. Knowledge of Cervical Cancer and Practice of Pap Smear Testing among Secondary School Teachers in Nnewi North Local Government Area of Anambra State, South Eastern Nigeria. Adv Sex Med. 2015; 5: 13-21. http://dx.doi.org/10.4236/asm.2015.52003

[15] AlHarfi MMA, Aljadidi JKA, Ali SI, et al. Awareness level of women living in Al-Ahsa, Saudi Arabia about the relationship between human papillomavirus and cervical cancer. Int $\mathrm{J}$ Med in Dev Ctries. 2019; 3: 592-96. doi:10.24911/IJMDC.51-1548091380 
[16] Anttila A, Ronco G. Description of the national situation of cervical cancer screening in the member states of the European Union. Eur J Cancer 2009; 45: 2685-708.

[17] Gari A, Asiri A, Mohammed A, et al. The awareness of the HPV's association with cervical cancer and the HPV vaccine among Saudi females. Life Sci J. 2012; 9: 2538-46.

\section{Tables}

Table 1. Demographic data of women in Najran, Saudi Arabia 


\begin{tabular}{|c|c|c|}
\hline \multicolumn{3}{|l|}{ Demographic data } \\
\hline & $n$ & $\%$ \\
\hline \multicolumn{3}{|l|}{ Age (years) } \\
\hline $18-29$ & 1,712 & 50.5 \\
\hline 30-39 & 1,010 & 29.8 \\
\hline $40-49$ & 569 & 16.8 \\
\hline ๑50 & 96 & 2.8 \\
\hline \multicolumn{3}{|l|}{ Nationality } \\
\hline Saudi & 3,210 & 94.8 \\
\hline Non-Saudi & 177 & 5.2 \\
\hline \multicolumn{3}{|l|}{ Education level } \\
\hline Illiterate & 56 & 1.7 \\
\hline Secondary and below & 947 & 28.0 \\
\hline University and above & 2,384 & 70.4 \\
\hline \multicolumn{3}{|l|}{ Occupation } \\
\hline Health provider & 151 & 4.5 \\
\hline School teacher & 703 & 20.8 \\
\hline University lecturer & 82 & 2.4 \\
\hline Other employee & 173 & 5.1 \\
\hline unemployee & 1,385 & 40.9 \\
\hline Medical student & 326 & 9.6 \\
\hline Non-medical student & 567 & 16.7 \\
\hline \multicolumn{3}{|l|}{ Marital status } \\
\hline Single & 1,397 & 41.2 \\
\hline Married & 1,834 & 54.1 \\
\hline Divorced & 116 & 3.4 \\
\hline Widowed & 40 & 1.2 \\
\hline \multicolumn{3}{|l|}{ Medical history } \\
\hline Nil & 3,021 & 89.2 \\
\hline Diabetes mellitus & 190 & 5.6 \\
\hline Hypertension & 94 & 2.8 \\
\hline Other & 82 & 2.4 \\
\hline \multicolumn{3}{|c|}{ Family history of any cancer } \\
\hline Yes & 736 & 21.7 \\
\hline No & 2,651 & 78.3 \\
\hline \multicolumn{3}{|l|}{ Parity } \\
\hline Nulliparous & 325 & 16.3 \\
\hline Multiparous & 1,665 & 83.7 \\
\hline \multicolumn{3}{|l|}{ Monthly income (SR) } \\
\hline$<5,000$ & 1,608 & 47.5 \\
\hline $5,000-15,000$ & 1,501 & 44.3 \\
\hline$>15000$ & 278 & 8.2 \\
\hline
\end{tabular}

Table 2: awareness and attitude of pap smear tests among women who married, divorce and widowed in Najran, Saudi Arabia. 


\begin{tabular}{|c|c|c|c|c|}
\hline \multicolumn{5}{|l|}{$n=1,990$} \\
\hline \multirow[t]{2}{*}{ Q } & \multicolumn{2}{|l|}{ Yes } & \multicolumn{2}{|l|}{ No } \\
\hline & $n$ & $\%$ & $n$ & $\%$ \\
\hline Do you know about screening tests (pap smear) for cervical cancer? & 1,024 & 51.5 & 966 & 48.5 \\
\hline Have you ever had a screening test (pap smear) for cervical cancer? & 282 & 14.2 & 1,708 & 85.8 \\
\hline \multicolumn{5}{|l|}{ If yes, which of the following prompted you to have the test? } \\
\hline & \multicolumn{2}{|l|}{$n$} & \multicolumn{2}{|l|}{$\%$} \\
\hline Advice from a doctor & \multicolumn{2}{|l|}{197} & \multicolumn{2}{|l|}{69.9} \\
\hline Advice applied from friends and family & \multicolumn{2}{|l|}{52} & \multicolumn{2}{|l|}{18.4} \\
\hline Advice from social media & \multicolumn{2}{|l|}{33} & \multicolumn{2}{|l|}{11.7} \\
\hline \multicolumn{5}{|l|}{ If no, which of the following prevented you from having the test? } \\
\hline & \multicolumn{2}{|l|}{$n$} & \multicolumn{2}{|l|}{$\%$} \\
\hline Do not know about it & \multicolumn{2}{|l|}{968} & \multicolumn{2}{|l|}{56.7} \\
\hline It hurts & \multicolumn{2}{|l|}{185} & \multicolumn{2}{|l|}{10.8} \\
\hline It is expensive & \multicolumn{2}{|l|}{31} & \multicolumn{2}{|l|}{1.8} \\
\hline It is not necessary & \multicolumn{2}{|l|}{338} & \multicolumn{2}{|l|}{19.8} \\
\hline Fear of results & \multicolumn{2}{|l|}{153} & \multicolumn{2}{|l|}{8.9} \\
\hline Religious or cultural reasons & \multicolumn{2}{|l|}{33} & \multicolumn{2}{|l|}{1.9} \\
\hline
\end{tabular}

Table 3: awareness and attitude of HPV vaccine among women in Najran, Saudi Arabia

le

\begin{tabular}{|c|c|c|c|c|}
\hline & \multicolumn{2}{|l|}{ Yes } & \multicolumn{2}{|l|}{ No } \\
\hline & $n$ & $\%$ & $n$ & $\%$ \\
\hline u think cervical cancer can be prevented by vaccination? & 2,983 & 88.1 & 404 & 11.9 \\
\hline 1 a vaccine be offered to women between the ages of 9 and 25 years to prevent cervical cancer? & 1,939 & 57.2 & 1448 & 42.8 \\
\hline
\end{tabular}

have had this vaccine, which of the followings prompted you to do so?

\begin{tabular}{l|l|l|}
\hline & $n$ & $\%$ \\
\hline Advice from a doctor & 192 & 36.2 \\
\hline Advice applied from friends and family & 143 & 26.9 \\
\hline Advice from social media & 195 & 36.8 \\
\hline
\end{tabular}

Table 4: Multiple logistic regression analyses for prediction of awareness of cervical cancer 


\begin{tabular}{|c|c|c|c|c|c|c|c|c|}
\hline \multirow[t]{3}{*}{ Predictors } & & \multicolumn{6}{|c|}{ General Knowledge Level } & \multirow[t]{3}{*}{$P$} \\
\hline & & \multicolumn{2}{|l|}{ Poor } & \multicolumn{2}{|c|}{ Moderate } & \multicolumn{2}{|c|}{ Good } & \\
\hline & & $n$ & $\%$ & $n$ & $\%$ & $n$ & $\%$ & \\
\hline \multirow{4}{*}{$\begin{array}{l}\text { Age } \\
\text { (years) }\end{array}$} & $18-29$ & 1,206 & 70.4 & 346 & 20.2 & 160 & 9.3 & \multirow[t]{4}{*}{$0.000^{*}$} \\
\hline & $30-39$ & 710 & 70.3 & 183 & 18.1 & 117 & 11.6 & \\
\hline & $40-49$ & 376 & 66.1 & 148 & 26 & 45 & 7.9 & \\
\hline & $\square 50$ & 76 & 79.2 & 18 & 18.8 & 2 & 2.1 & \\
\hline \multirow[t]{2}{*}{ Nationality } & Saudi & 2,237 & 69.7 & 663 & 20.7 & 310 & 9.7 & \multirow[t]{2}{*}{0.466} \\
\hline & Non-Saudi & 131 & 74 & 32 & 18.1 & 14 & 7.9 & \\
\hline \multirow[t]{3}{*}{ Education level } & Illiterate & 45 & 80.4 & 7 & 12.5 & 4 & 7.1 & \multirow[t]{3}{*}{$0.003^{*}$} \\
\hline & Secondary and below & 704 & 74.3 & 166 & 17.5 & 77 & 8.1 & \\
\hline & University and above & 1,619 & 67.9 & 522 & 21.9 & 243 & 10.2 & \\
\hline \multirow[t]{7}{*}{ Occupation } & Health provider & 84 & 55.6 & 44 & 29.1 & 23 & 15.2 & \multirow[t]{7}{*}{$0.000 *$} \\
\hline & School teacher & 452 & 64.3 & 178 & 25.3 & 73 & 10.4 & \\
\hline & University lecturer & 61 & 74.4 & 13 & 15.9 & 8 & 9.8 & \\
\hline & Other employee & 119 & 68.8 & 34 & 19.7 & 20 & 11.6 & \\
\hline & Non-employee & 1,047 & 75.6 & 227 & 16.4 & 111 & 8 & \\
\hline & Medical student & 187 & 57.4 & 88 & 27 & 51 & 15.6 & \\
\hline & Non-medical student & 418 & 73.7 & 111 & 19.6 & 38 & 6.7 & \\
\hline \multirow[t]{4}{*}{ Marital status } & Single & 971 & 69.5 & 291 & 20.8 & 135 & 9.7 & \multirow[t]{4}{*}{0.918} \\
\hline & Married & 1,287 & 70.2 & 374 & 20.4 & 173 & 9.4 & \\
\hline & Divorced & 80 & 69 & 25 & 21.6 & 11 & 9.5 & \\
\hline & Widowed & 30 & 75 & 5 & 12.5 & 5 & 12.5 & \\
\hline \multirow[t]{4}{*}{ Medical history } & Nil & 2,108 & 69.8 & 627 & 20.8 & 286 & 9.5 & \multirow[t]{4}{*}{0.472} \\
\hline & Diabetes mellitus & 134 & 70.5 & 33 & 17.4 & 23 & 12.1 & \\
\hline & Hypertension & 67 & 71.3 & 16 & 17 & 11 & 11.7 & \\
\hline & Other & 59 & 72 & 19 & 23.2 & 4 & 4.9 & \\
\hline \multirow[t]{2}{*}{ Family history } & Yes & 460 & 62.5 & 157 & 21.3 & 119 & 16.2 & \multirow[t]{2}{*}{$0.000^{*}$} \\
\hline & No & 1,908 & 72 & 538 & 20.3 & 205 & 7.7 & \\
\hline \multirow[t]{3}{*}{ Parity } & Nulliparous & 245 & 75.4 & 52 & 16 & 28 & 8.6 & \multirow[t]{3}{*}{0.239} \\
\hline & Multiparous & 1,152 & 69.2 & 352 & 21.1 & 161 & 9.7 & \\
\hline & Single & 971 & 69.5 & 291 & 20.8 & 135 & 9.7 & \\
\hline \multirow[t]{3}{*}{ Monthly income (SR) } & $<5,000$ & 1,181 & 73.4 & 302 & 18.8 & 125 & 7.8 & \multirow[t]{3}{*}{$0.000 *$} \\
\hline & $5,000-15,000$ & 1,003 & 66.8 & 333 & 22.2 & 165 & 11 & \\
\hline & $>15,000$ & 184 & 66.2 & 60 & 21.6 & 34 & 12.2 & \\
\hline
\end{tabular}




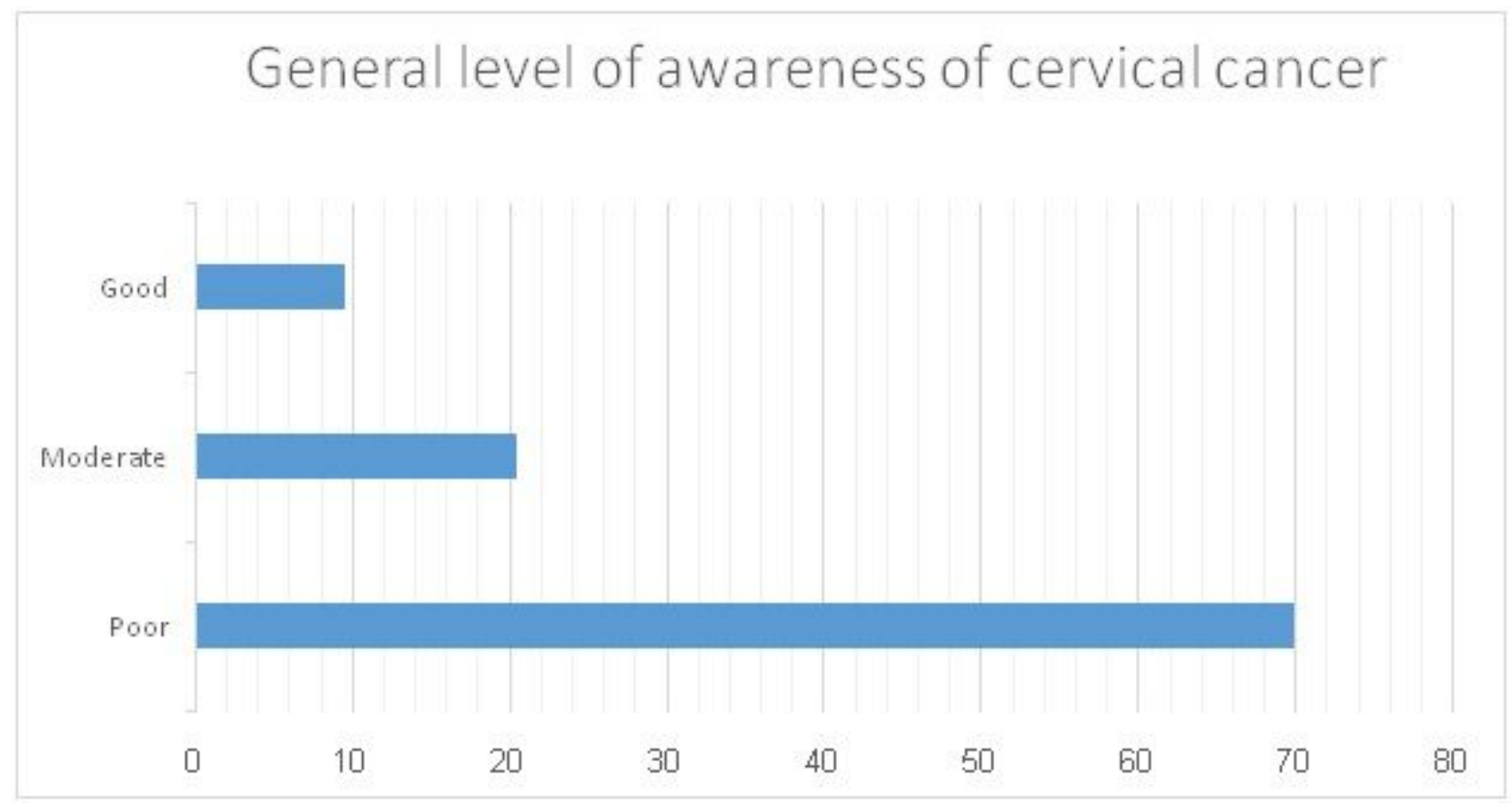

\section{Figure 1}

General level of awareness risk of cervical cancer

\section{Supplementary Files}

This is a list of supplementary files associated with this preprint. Click to download.

- Availabilityofdataandmaterial.xlsx 